\title{
Cannabinoid hyperemesis syndrome
}

\author{
Chelsey King MSc, Andrew Holmes MD
}

\section{Cannabinoid hyperemesis syndrome (CHS) is a new and underrecognized clinical syndrome}

Cannabis is the most widely used illicit drug in Canada, with $42 \%$ of adults reporting usage during their lifetime. ${ }^{1}$ Cannabinoid hyperemesis syndrome (CHS) is characterized by recurrent episodes of intractable nausea and vomiting in patients who have been using cannabis daily for years (Box 1)..$^{2-4}$ Patients with CHS may have numerous visits with their physician before diagnosis, which highlights the underrecognition of this syndrome. ${ }^{5}$

Box 1: Features of cannabinoid hyperemesis syndrome ${ }^{2,3}$

- Current, heavy cannabis use

- Abdominal pain, epigastric or periumbilical

- Recurrent episodes of severe nausea and intractable vomiting

- Compulsive bathing with symptom relief

- Resolution of symptoms with cannabis cessation

- Failure of standard antiemetics to resolve nausea and vomiting
The differential diagnosis for CHS is large

Life-threatening causes of nausea and vomiting, such as intestinal obstruction or perforation and pancreatitis, must be ruled out. ${ }^{2,5}$ Cannabinoid hyperemesis syndrome is most often confused with cyclic vomiting syndrome. Patients with cyclic vomiting syndrome are more likely to have a history of psychiatric illness and a personal or family history of migraines. ${ }^{2}$

\section{References}

1. Canadian Alcohol and Drug Use Monitoring Survey. Ottawa: Statistics Canada; 2014. Available: www. hc-sc.gc.ca/hc-ps/drugs-drogues/stat/2012/summary -sommaire-eng.php (accessed 2014 Aug 21).

2. Chen J, McCarron RM. Cannabinoid hyperemesis syndrome: a result of chronic, heavy cannabis use. Curr Psych 2013;10:48-54.

3. Simonetto DA, Oxentenko AM, Herman ML, et al. Cannabinoid hyperemesis: a case series of 98 patients. Mayo Clin Proc 2012;87:114-9.
The exact mechanism of hyperemesis associated with long-term cannabis use is unknown

Tetrahydrocannabinol (THC), the active compound in cannabis, binds to cannabinoid receptors $\left(\mathrm{CB}_{1}\right.$ and $\left.\mathrm{CB}_{2}\right) .^{5}$ Antiemetic properties are mediated by activation of $\mathrm{CB}_{1}$ in the hypothalamus, and nausea and vomiting properties by activation of $\mathrm{CB}_{1}$ in the enteric nervous system. Hyperemesis in heavy cannabis users is thought to occur because of the accumulation of THC in fatty tissues, which leads to enteric stimulation that overrides the effects of the central nervous system. ${ }^{2,5}$

4. Allen JH, Moore GM, Heddle R, et al. Cannabinoid hyperemesis: cyclical hyperemesis in association with chronic cannabis abuse. Gut 2004;53: 1566-70.

5. Galli JA, Sawaya RA, Friedenberg FK. Cannabinoid hyperemesis syndrome. Curr Drug Abuse Rev 2011;4:241-9

6. Habboushe J, Sedor J. Cannabinoid hyperemesis acute renal failure: a common sequela of cannabinoid hyperemesis syndrome. Am J Emerg Med 2014; 32:690.e1-2.
CHS is characterized by the triad of long-term cannabis abuse, cyclic episodes of nausea and vomiting, and compulsive bathing

Patients with CHS have a history of daily use of natural or synthetic cannabis over a period of years. ${ }^{5}$ They experience incapacitating vomiting that sometimes occurs more than 20 times per day and can last 24-28 hours. ${ }^{2}$ Patients report taking numerous hot showers or baths with relief of symptoms, a learned behaviour termed compulsive bathing, which is pathognomonic for CHS. ${ }^{2}$

Treatment is supportive, and remission requires abstinence from cannabis use

Permanent remission of CHS requires cessation of cannabis use. ${ }^{4}$ Standard antiemetics fail to relieve vomiting, but relief has been reported with lorazepam and haloperidol. ${ }^{2}$ Case reports of acute renal failure secondary to CHS have been noted, all of which resolved with intravenous hydration. ${ }^{6}$

\section{Competing interests: None declared.}

This article has been peer reviewed.

Affiliations: Department of Medicine (King, Holmes), Dalhousie University, Halifax, NS; Department of Emergency Medicine (Holmes), Cape Breton Regional Hospital, Sydney, NS

Correspondence to: Chelsey King, chelsey.king @ dal.ca

CMAJ 2015. DOI:10.1503/cmaj.140154 